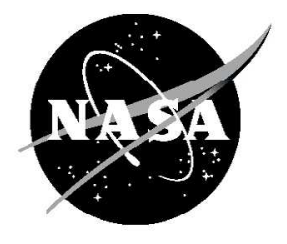

\title{
Determination of Chemical Kinetic Rate Constants of a Model for Carbothermal Processing of Lunar Regolith Simulant Using Methane
}

\author{
R. Balasubramaniam \\ National Center for Space Exploration Research, Glenn Research Center, Cleveland, Ohio \\ S. Gokoglu \\ Glenn Research Center, Cleveland, Ohio \\ U. Hegde \\ National Center for Space Exploration Research, Glenn Research Center, Cleveland, Ohio
}




\section{NASA STI Program . . . in Profile}

Since its founding, NASA has been dedicated to the advancement of aeronautics and space science. The NASA Scientific and Technical Information (STI) program plays a key part in helping NASA maintain this important role.

The NASA STI Program operates under the auspices of the Agency Chief Information Officer. It collects, organizes, provides for archiving, and disseminates NASA's STI. The NASA STI program provides access to the NASA Aeronautics and Space Database and its public interface, the NASA Technical Reports Server, thus providing one of the largest collections of aeronautical and space science STI in the world. Results are published in both non-NASA channels and by NASA in the NASA STI Report Series, which includes the following report types:

- TECHNICAL PUBLICATION. Reports of completed research or a major significant phase of research that present the results of NASA programs and include extensive data or theoretical analysis. Includes compilations of significant scientific and technical data and information deemed to be of continuing reference value. NASA counterpart of peer-reviewed formal professional papers but has less stringent limitations on manuscript length and extent of graphic presentations.

- TECHNICAL MEMORANDUM. Scientific and technical findings that are preliminary or of specialized interest, e.g., quick release reports, working papers, and bibliographies that contain minimal annotation. Does not contain extensive analysis.

- CONTRACTOR REPORT. Scientific and technical findings by NASA-sponsored contractors and grantees.
- CONFERENCE PUBLICATION. Collected papers from scientific and technical conferences, symposia, seminars, or other meetings sponsored or cosponsored by NASA.

- SPECIAL PUBLICATION. Scientific, technical, or historical information from NASA programs, projects, and missions, often concerned with subjects having substantial public interest.

- TECHNICAL TRANSLATION. Englishlanguage translations of foreign scientific and technical material pertinent to NASA's mission.

Specialized services also include creating custom thesauri, building customized databases, organizing and publishing research results.

For more information about the NASA STI program, see the following:

- Access the NASA STI program home page at http://www.sti.nasa.gov

- E-mail your question via the Internet to help@ sti.nasa.gov

- Fax your question to the NASA STI Help Desk at $443-757-5803$

- Telephone the NASA STI Help Desk at 443-757-5802

- Write to: NASA Center for AeroSpace Information (CASI) 7115 Standard Drive Hanover, MD 21076-1320 
NASA/TM-2009-215617

AIAA-2009-1390

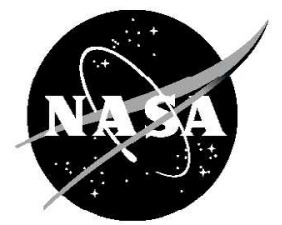

\title{
Determination of Chemical Kinetic Rate Constants of a Model for Carbothermal Processing of Lunar Regolith Simulant Using Methane
}

\author{
R. Balasubramaniam \\ National Center for Space Exploration Research, Glenn Research Center, Cleveland, Ohio \\ S. Gokoglu \\ Glenn Research Center, Cleveland, Ohio \\ U. Hegde \\ National Center for Space Exploration Research, Glenn Research Center, Cleveland, Ohio
}

Prepared for the

47th Aerospace Sciences Meeting

sponsored by the American Institute of Aeronautics and Astronautics

Orlando, Florida, January 5-8, 2009

National Aeronautics and

Space Administration

Glenn Research Center

Cleveland, Ohio 44135 


\section{Acknowledgments}

The authors thank Diane Linne, NASA Glenn Research Center, for useful discussions and Robert Gustafson, Orbital Technologies Corporation, for providing the data reported in table 1 in this paper. The authors gratefully acknowledge the support of this work by the In-Situ Resource Utilization Project which is a part of the NASA Exploration Technology Development Program.

Level of Review: This material has been technically reviewed by technical management.

Available from

NASA Center for Aerospace Information 7115 Standard Drive

Hanover, MD 21076-1320
National Technical Information Service 5285 Port Royal Road Springfield, VA 22161

Available electronically at http://gltrs.grc.nasa.gov 


\title{
Determination of Chemical Kinetic Rate Constants of a Model for Carbothermal Processing of Lunar Regolith Simulant Using Methane
}

\author{
R. Balasubramaniam \\ National Center for Space Exploration Research \\ Glenn Research Center \\ Cleveland, Ohio 44135 \\ S. Gokoglu \\ National Aeronautics and Space Administration \\ Glenn Research Center \\ Cleveland, Ohio 44135 \\ U. Hegde \\ National Center for Space Exploration Research \\ Glenn Research Center \\ Cleveland, Ohio 44135
}

\begin{abstract}
We have previously developed a chemical conversion model of the carbothermal processing of lunar regolith using methane to predict the rate of production of carbon monoxide. In this carbothermal process, gaseous methane is pyrolyzed as it flows over the hot surface of a molten zone of lunar regolith and is converted to carbon and hydrogen. Hydrogen is carried away by the exiting stream of gases and carbon is deposited on the melt surface. The deposited carbon mixes with the melt and reacts with the metal oxides in it to produce carbon monoxide that bubbles out of the melt. In our model, we assume that the flux of carbon deposited is equal to the product of the surface reaction rate constant $\gamma$ and the concentration of methane adjacent to the melt surface. Similarly, the rate of consumption of carbon per unit volume in the melt is equal to the product of the melt reaction rate constant $k$ and the concentrations of carbon and metal oxide in the melt.

In this paper, we describe our effort to determine $\gamma$ and $k$ by comparison of the predictions from our model with test data obtained by ORBITEC (Orbital Technologies Corporation). The concentration of methane adjacent to the melt surface is a necessary input to the model. It is inferred from the test data by a mass balance of methane, adopting the usual assumptions of the continuously-stirred-tank-reactor model, whereby the average concentration of a given gaseous species equals its exit concentration. The reaction rates $\gamma$ and $k$ have been determined by a non-linear least-squares fit to the test data for the production of carbon monoxide and the fraction of the incoming methane that is converted.

The comparison of test data with our model predictions using the determined chemical kinetic rate constants provides a consistent interpretation of the process over the full range of temperatures, pressures, and methane flow rates used in the tests, thereby increasing our confidence to use the model for scale-up purposes.
\end{abstract}

\section{Nomenclature}

Stoichiometric coefficient

Melt surface area, $\mathrm{m}^{2}$

Concentration, moles $/ \mathrm{m}^{3}$

$C_{m}$ Concentration of methane in the gas phase adjacent to the melt surface, moles $/ \mathrm{m}^{3}$

$f \quad$ Fraction of incoming methane converted

$k \quad$ Melt reaction rate constant, $\mathrm{m}^{3} /($ moles $\cdot \mathrm{s})$

$\dot{m} \quad$ Molar flow rate, moles/s

$t \quad$ Scaled (dimensionless) time, $t=\frac{t^{*}}{1 / k \beta_{0}}$

$t^{*} \quad$ Time, $\mathrm{s}$

$V \quad$ Melt volume, $\mathrm{m}^{3}$ 


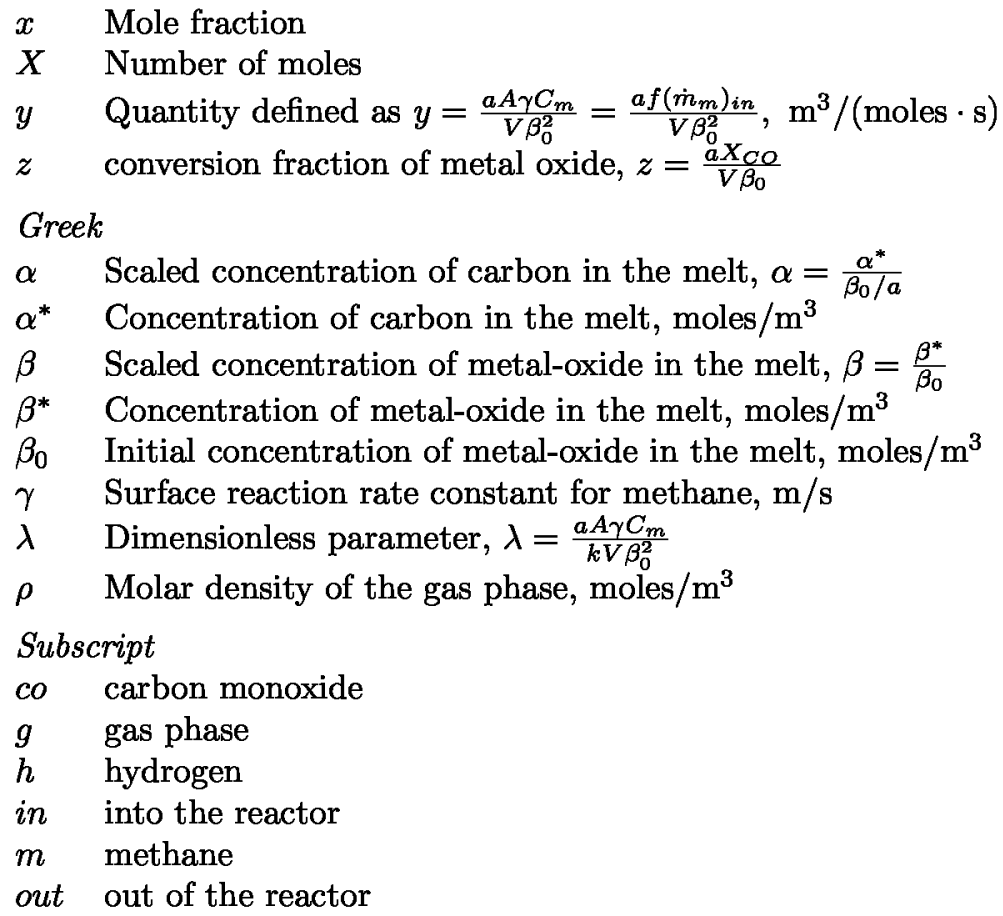

\section{Introduction}

A key element in NASA's plans for exploration of the Moon involves the production of oxygen for life support as well as use as a propellant. Sanders et al. ${ }^{1}$ describe NASA's current plans for In-Situ Resource Utilization (ISRU). Various processes are being considered for the extraction of oxygen that is available in the lunar regolith as oxides of various materials. These processes include reduction using hydrogen, molten salt electrolysis, and carbothermal processing.

The carbothermal processing of lunar regolith using methane as the source for carbon was first performed by Rosenberg and co-workers at Aerojet in the 1960s (Rosenberg et al.). ${ }^{2}$ Currently it is being developed further for lunar exploration by Orbital Technologies Corporation (ORBITEC). ${ }^{3}$ We have previously developed a chemical conversion model of the carbothermal processing of lunar regolith using methane to predict the rate of production of carbon monoxide (Balasubramaniam et al.) ${ }^{4}$ In this process, gaseous methane is pyrolyzed above the hot surface of a molten zone of lunar regolith, depositing carbon on the surface and generating hydrogen which is carried away by the exiting stream of gas. The deposited carbon mixes with the melt and reacts with the metal oxides in it to produce carbon monoxide that bubbles out of the melt. Oxygen is ultimately produced by processing the carbon monoxide in reactors downstream. In our model, we assume that the flux of carbon deposited $\left(\mathrm{moles} /\left(\mathrm{m}^{2} \cdot \mathrm{s}\right)\right)$ is equal to the product of the surface reaction rate constant $\gamma(\mathrm{m} / \mathrm{s})$ and the concentration of methane $\left(\mathrm{moles} / \mathrm{m}^{3}\right)$ adjacent to the melt surface. The rate of consumption of carbon per unit volume in the melt is equal to the product of the melt reaction rate constant $\mathrm{k}\left(\mathrm{m}^{3} /(\right.$ moles $\left.\cdot \mathrm{s})\right)$ and the concentrations of carbon and metal oxide in the melt $\left(\mathrm{moles} / \mathrm{m}^{3}\right)$.

In this paper we describe our effort to determine $\gamma$ and $k$ by comparison of the predictions from our model with data from ORBITEC's Test Series- $1 .{ }^{5}$ The data from Test Series- 1 is reproduced in Table 1 . This series of tests was conducted using the lunar regolith simulant JSC-1A. A $200 \mathrm{~W}$ laser was used to melt the material and maintain it at the chosen operating temperature. This test series was a part of ORBITEC's Statistical Experiment Design to investigate the main effects of processing pressure, temperature, and methane flow rate on the carbothermal reduction process, as well as the interactions that occur among these test variables. The chemical processing time in these tests was $80 \mathrm{~min}$. 


\section{Model}

\section{A. Background}

Figure 1 shows a schematic of the carbothermal process. A model of the processing of lunar regolith by this method is described in Ref[4]. It is assumed that carbon deposition occurs on the hot molten surface via a

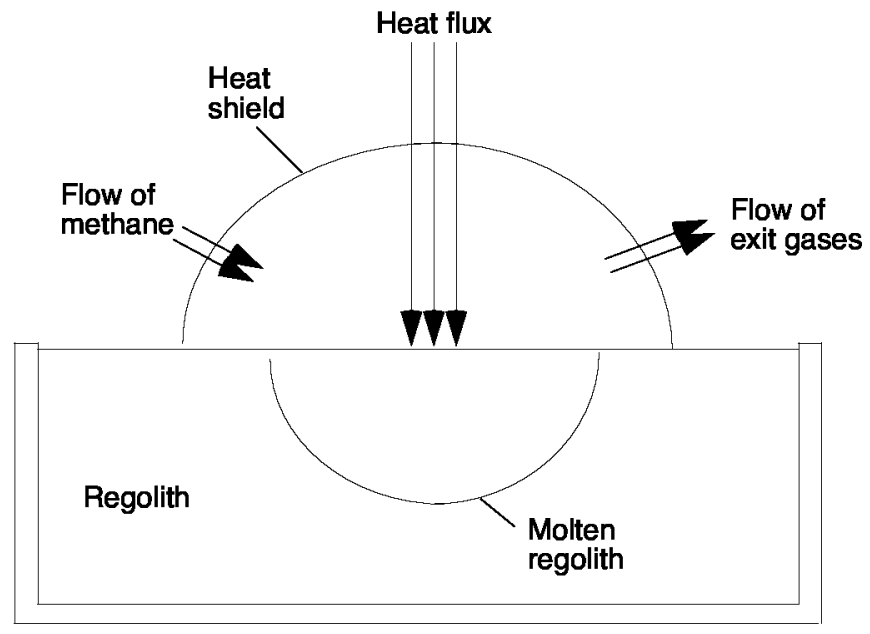

Figure 1. Sketch of the carbothermal process

surface reaction. This surface reaction is regarded as first order with respect to a gaseous carbon-containing species and produces solid carbon and gaseous hydrogen. This carbon-containing species need not necessarily be methane; it can be any of several carbon-containing species which may be produced by the gas-phase pyrolysis of methane. Since all these carbon-containing species are ultimately produced from methane, the model lumps all possible pathways to deposit carbon on the surface into a single process. This deposition process is described by a first-order surface reaction of methane. Thus, the flux of carbon deposited on the surface of the melt is assumed to be proportional to the concentration of methane in the gas phase above the melt. The proportionality constant needs to be determined by comparison of the model predictions with the test data. The concentration of methane above the melt is assumed constant by its continuous flow in the gas phase. The deposited carbon and the metal oxide in the molten regolith are assumed to undergo a single-step, second-order chemical reaction (first-order with respect to both carbon and the metal oxide). This reaction rate constant also needs to be determined by comparison of the model predictions with the test data. Our current model does not account for spatial gradients of the concentration of carbon or of the metal oxide within the melt; the zone is regarded as well-mixed. This would be the case when the zone is sufficiently small that the diffusion of carbon within the melt is rapid, or more likely, when there is flow within the melt caused by the evolution of bubbles, natural convection, and thermocapillary forces. In some of the tests in Ref[5], a crust or cap of carbon forms on the surface of the melt (see Table 1). The formation of a carbon cap indicates that the deposited carbon did not get mixed in the melt, or more likely, did not go into solution in the melt. We do not consider the formation of a carbon cap in our model. We assume that the molten zone is established and maintained by heating the regolith by suitable means. The heat transfer aspects of the problem are not analyzed here. The processes of chemical conversion and heat transfer within the molten regolith are assumed to be uncoupled.

\section{B. Reaction in the melt}

The chemical conversion model in Ref[4] assumes that the concentration of methane in the gas phase is maintained constant. Carbon is deposited on the melt by a first-order surface reaction. Within the melt the metal oxide and carbon are assumed to be spatially uniform, and undergo a single-step reaction that is of first order in each species. The mass balance of metal oxide and carbon were described as follows.

$$
\frac{d \alpha^{*}}{d t^{*}}=\frac{A \gamma C_{m}}{V}-k \alpha^{*} \beta^{*}
$$




$$
\frac{d \beta^{*}}{d t^{*}}=-a k \alpha^{*} \beta^{*}
$$

where $V=$ melt volume $\left(\mathrm{m}^{3}\right), A=$ melt surface area $\left(\mathrm{m}^{2}\right), a=$ stoichiometric coefficient of the oxide term in its reaction with carbon $\left(\approx 0.5\right.$ for $\left.\mathrm{SiO}_{2}\right)$, and $C_{m}=$ concentration of methane in the gas phase adjacent to the melt surface $\left(\mathrm{moles} / \mathrm{m}^{3}\right)$. The initial conditions are that at $t^{*}=0$, there is no carbon present in the melt and concentration of the metal oxide is $\beta_{0}$. A closed form solution can be obtained and is given below.

$$
\begin{gathered}
\alpha=\beta-1+\lambda t \\
\beta=\frac{2 \sqrt{\lambda} \operatorname{Exp}\left(t-\frac{\lambda}{2} t^{2}\right)}{2 \sqrt{\lambda}+\operatorname{Exp}\left(\frac{1}{2 \lambda}\right) \sqrt{2 \pi}\left[\operatorname{Erf}\left(\frac{1}{\sqrt{2 \lambda}}\right)+\operatorname{Erf}\left(\frac{t \lambda-1}{\sqrt{2 \lambda}}\right)\right]}
\end{gathered}
$$

where $\alpha=\frac{\alpha^{*}}{\beta_{0} / a}$ and $\beta=\frac{\beta^{*}}{\beta_{0}}$ denote dimensionless concentrations of carbon and metal oxide, respectively, and $t=\frac{t^{*}}{1 /\left(k \beta_{0}\right)}$ denotes scaled time. $\lambda=\frac{a A \gamma C_{m}}{k V \beta_{0}^{2}}$ is a dimensionless parameter that is a measure of the relative strength of the surface reaction rate of methane to the reaction rate between carbon and metal oxide in the melt.

\section{Gas phase above the melt}

In order to apply the melt reaction model described above, the gas-phase concentration of methane $C_{m}$ must be known. If the gas phase is flooded with pure methane by maintaining a high flow rate so that the mole fraction of methane is nearly unity everywhere, then $C_{m}$ can be determined from the conditions of the incoming stream of methane and the temperature of the melt surface. If a significant fraction of the incoming methane is consumed by the surface reaction to deposit carbon on the melt, then $C_{m}$ must be determined by considering the transport of various species in the gas phase.

We consider the mass balance of methane, hydrogen and carbon monoxide in the gas phase above the melt. (We neglect the production of carbon dioxide in the melt. The experiments at ORBITEC indeed show that the amount of carbon dioxide detected is only a few percent of the amount of carbon monoxide produced.) Let subscripts $m, h$ and $c o$ denote methane, hydrogen and carbon monoxide, respectively, and subscripts in and out denote quantities at the inlet and exit of the reactor. Neglecting diffusion, the gas-phase molar balance for these species can be written as

$$
\begin{gathered}
\left(\dot{m}_{m}\right)_{\text {in }}-\left(\dot{m}_{m}\right)_{\text {out }}=\gamma A C_{m}+V_{g} \frac{d C_{m}}{d t^{*}} \\
-\left(\dot{m}_{h}\right)_{o u t}=-2 \gamma A C_{m}+V_{g} \frac{d C_{h}}{d t^{*}} \\
-\left(\dot{m}_{c o}\right)_{o u t}=-\frac{V \beta_{0}^{2} k}{a} \alpha \beta+V_{g} \frac{d C_{c o}}{d t^{*}}
\end{gathered}
$$

where $V_{g}$ is the volume of the gas phase and $\dot{m}$ is the molar flow rate of a given species. The term involving $\gamma$ in $\mathrm{Eq}(5)$ represents the consumption of methane by the chemical reaction at the melt surface. In writing the mass balance for hydrogen, we have made use of the fact that the number of moles of hydrogen produced is twice the number of moles of methane pyrolyzed, which follows from stoichiometry. The production term in Eq (7) represents the carbon monoxide produced by the reaction in the melt that bubbles out of the melt and is released into the gas phase.

We assume that the temperature and pressure are constant in the gas phase, and the gases obey the ideal-gas law. Under these conditions, the total molar density of the gases $\left(\mathrm{moles} / \mathrm{m}^{3}\right) \rho=C_{m}+C_{h}+C_{c o}$ is a constant. The addition of the three equations given above yields

$$
\left(\dot{m}_{m}\right)_{i n}-\dot{M}_{o u t}=-\gamma A C_{m}-\frac{V \beta_{0}^{2} k}{a} \alpha \beta
$$

where $\dot{M}_{\text {out }}=\left(\dot{m}_{m}\right)_{\text {out }}+\left(\dot{m}_{h}\right)_{\text {out }}+\left(\dot{m}_{c o}\right)_{\text {out }}$. 
We further assume that:

(i) the reactor can be modeled as a continuously-stirred-tank-reactor (CSTR) which implies that the average concentration of a given species in the reactor equals its exit concentration. Thus, $C_{m}=$ $\left(C_{m}\right)_{o u t}=x_{m} \rho$ where $x_{m}$ is the mole fraction of methane.

(ii) a quasi-steady state holds, and the unsteady (accumulation) term in the mass balance equation for methane can be neglected.

(iii) a fraction $f$ (taken to be a constant) of the incoming methane is pyrolyzed.

The mass balance for methane and the overall gas-phase mass balance can then be written as follows.

$$
\begin{gathered}
f\left(\dot{m}_{m}\right)_{i n}=\gamma A C_{m}=\gamma A \rho x_{m} \\
\frac{(1-f)\left(\dot{m}_{m}\right)_{i n}}{x_{m}}=\left(\dot{m}_{m}\right)_{i n}+\gamma A \rho x_{m}+\frac{V \beta_{0}^{2} k}{a} \alpha \beta
\end{gathered}
$$

We note that when the flow rate of methane is large compared to the rate at which it is consumed by the

reaction on the melt surface and the rate of production of carbon monoxide (i.e., $\left.\frac{\gamma A C_{m}}{\left(\dot{m}_{m}\right)_{i n}}, \frac{V \beta_{0}^{2} k}{\left(\dot{m}_{m}\right)_{i n}} \ll 1\right)$, Eqs (9) and (10) show that $f \ll 1$ and $x_{m} \rightarrow 1$. This represents the case where the gas phase above the melt is flooded by methane, as discussed earlier.

\section{Determination of $k$ and $\gamma$}

It can be shown that the amount of carbon monoxide produced, $X_{C O}$ (moles) is given by

$$
X_{C O}=\frac{V \beta_{0}}{a}(1-\beta(t))
$$

Substituting the expression for $\beta$ from Eq (4), this equation may be written as

$$
\frac{2 \sqrt{\frac{y}{k}} \operatorname{Exp}\left(\mathrm{k} \beta_{0} \mathrm{t}^{*}-\frac{1}{2} \mathrm{yk} \beta_{0}^{2} \mathrm{t}^{* 2}\right)}{2 \sqrt{\frac{y}{k}}+\operatorname{Exp}\left(\frac{\mathrm{k}}{2 \mathrm{y}}\right) \sqrt{2 \pi}\left[\operatorname{Erf}\left(\sqrt{\frac{\mathrm{k}}{2 \mathrm{y}}}\right)+\operatorname{Erf}\left(\sqrt{\left(\frac{\mathrm{k}}{2 \mathrm{y}}\right.}\left(\mathrm{y} \beta_{0} \mathrm{t}^{*}-1\right)\right)\right]}=1-z
$$

where $y=\frac{a A \gamma C_{m}}{V \beta_{0}^{2}}=\frac{a f\left(\dot{m}_{m}\right)_{i n}}{V \beta_{0}^{2}}\left(\mathrm{~m}^{3} /(\right.$ moles $\left.\cdot \mathrm{s})\right), z=$ conversion fraction of metal oxide $=\frac{a X X_{C O}}{V \beta_{0}}$. We have substituted $\gamma A C_{m}=f\left(\dot{m}_{m}\right)_{i n}$ (from Eq (9)) in the definition of $y$ to eliminate $\gamma$ in the expression for $y$. Note that $y / k$ is a dimensionless quantity $(y / k=\lambda) . y$ is proportional to the rate of carbon deposited per unit volume of the melt.

The reaction rate constant $k$ is obtained from the above expression by a non-linear least-squares fit. From the perspective of the fitting procedure, $y$ is the variable, $1-z$ is the data and $k$ is the parameter to be obtained.

From Eqs (3), (9) and (10), the following expression can be obtained for $\gamma$.

$$
\gamma=\frac{f(1+f+f \beta t)}{1-f} \frac{\left(\dot{m}_{m}\right)_{i n}}{A \rho}+\frac{k V \beta_{0}^{2}}{a A \rho}\left(\frac{f}{1-f}\right) \beta(\beta-1)
$$

Once $k$ is determined, $\gamma$ can then be obtained from a least-squares fit to this expression. 


\section{Results}

The Test Series- 1 data $^{5}$ is tabulated in Table 1 . The area of the melt-gas surface is necessary in analyzing the data. We have assumed that the processed regolith has a hemispherical shape to determine this area. We have also assumed that JSC-1A has a maximum oxygen yield of $25 \%$ in calculating $\beta_{0}$. This is consistent with the extraction of all the available oxygen from $\mathrm{SiO}_{2}$ that JSC-1A contains, which is $46.2 \%$ by weight. ${ }^{6}$ For another lunar simulant JSC-1, it has been estimated that the maximum oxygen yield is approximately $28 \%$ for reduction of $\mathrm{SiO}_{2}, \mathrm{FeO}$ and $\mathrm{Fe}_{2} \mathrm{O}_{3}$ to $\mathrm{Si}$ and $\mathrm{Fe}$, and $\mathrm{TiO}_{2}$ to $\mathrm{Ti}_{2} \mathrm{O}_{3} .{ }^{7}$ The initial concentration of the metal oxide in the simulant is assumed to be $\beta_{0}$.

Table 1. Summary of Results from Test Series \#1

\begin{tabular}{|c|c|c|c|c|c|c|c|c|c|c|c|}
\hline & \multicolumn{3}{|c|}{ Experimental Variables } & \multicolumn{3}{|c|}{ Results } & \multicolumn{5}{|c|}{ Additional Observations } \\
\hline $\begin{array}{c}\text { Test } \\
\text { Number }\end{array}$ & $\begin{array}{c}\text { Target } \\
\text { Processing } \\
\text { Temperature } \\
\text { (C) }\end{array}$ & $\begin{array}{c}\text { Processing } \\
\text { Pressure } \\
\text { (psia) }\end{array}$ & $\begin{array}{c}\text { Methane } \\
\text { Flow Rate } \\
\text { (sccm) }\end{array}$ & $\begin{array}{c}\text { Oxygen } \\
\text { Produced } \\
\text { (g) }\end{array}$ & $\begin{array}{c}\text { Oxygen } \\
\text { Yield } \\
\text { (\%) }\end{array}$ & \begin{tabular}{|c|} 
Carbon \\
Recovered \\
(\%)
\end{tabular} & $\begin{array}{c}\text { Average } \\
\text { Processing } \\
\text { Temperature* } \\
\text { (C) }\end{array}$ & $\begin{array}{l}\text { Maximum } \\
\text { Reflector } \\
\text { Temperature } \\
\text { (C) }\end{array}$ & $\begin{array}{l}\text { Regolith } \\
\text { Processed } \\
\text { (g) }\end{array}$ & $\begin{array}{c}\text { Amount of } \\
\text { Methane } \\
\text { Pyrolyzed } \\
(\%)\end{array}$ & \begin{tabular}{c|} 
Time to \\
Form Carbon \\
Cap (min.)
\end{tabular} \\
\hline 1 & 1850 & 9 & 6.05 & 0.340 & 12.6 & 79.1 & 1846 & 609 & 2.702 & 78.1 & no cap \\
\hline 2 & 1650 & 9 & 11.56 & 0.302 & 13.3 & 62.0 & 1735 & 597 & 2.268 & 65.8 & 55.2 \\
\hline 3 & 1850 & 15 & 11.56 & 0.402 & 10.5 & 73.3 & 1890 & 578 & 3.845 & 74.5 & 58.9 \\
\hline 4 & 1850 & 3 & 17.18 & 0.160 & 2.0 & 75.8 & 1911 & 601 & 8.119 & 59.6 & no cap \\
\hline 5 & 1850 & 15 & 11.56 & 0.342 & 9.5 & 67.7 & 1913 & 525 & 3.587 & 71.6 & 60.8 \\
\hline 6 & 1750 & 9 & 17.18 & 0.301 & 11.0 & 52.6 & 1713 & 636 & 2.740 & 56.1 & 32.1 \\
\hline 7 & 1650 & 3 & 6.05 & 0.219 & 8.7 & 76.7 & 1722 & 596 & 2.516 & 56.7 & no cap \\
\hline 8 & 1650 & 15 & 17.18 & 0.295 & 15.6 & 50.1 & 1702 & 612 & 1.889 & 54.9 & 16.6 \\
\hline 9 & 1750 & 3 & 11.56 & 0.325 & 7.6 & 69.8 & 1713 & 613 & 4.298 & 59.1 & no cap \\
\hline 10 & 1750 & 15 & 6.05 & 0.289 & 8.2 & 83.3 & $1666^{* *}$ & 597 & 3.514 & 77.7 & no cap \\
\hline 11 & 1650 & 3 & 6.05 & 0.235 & 6.1 & 79.9 & 1640 & 638 & 3.860 & 56.9 & no cap \\
\hline
\end{tabular}

We have determined that $k=4.512 \times 10^{-8} \mathrm{~m}^{3} /($ moles $\cdot \mathrm{s})$ and $\gamma=0.0404 \mathrm{~m} / \mathrm{s}$ are the best-fit values to the data in Table 1. The Test Series-1 data in Table 1 is plotted in the variables used in the statistical fit $(1-z$ versus $y)$ in Figure 2 and the best fit curve for $k$ is shown. The conversion fraction $z$ is the fraction of the initial metal oxide present in the simulant that has reacted. It is readily obtained as the ratio of the actual oxygen yield in each test to the maximum possible oxygen yield. The data in Figure 2 and all subsequent figures shown are color-coded as follows: green symbols are used to represent data in Table 1 where no carbon cap is formed (test number $1,4,7,9,10,11$ ), with a darker green used for test number 4; blue symbols represent data where the carbon cap formation is relatively slow (test number $2,3,5$ ) and red symbols are used when the carbon cap formation is relatively fast (test number 6,8 ).

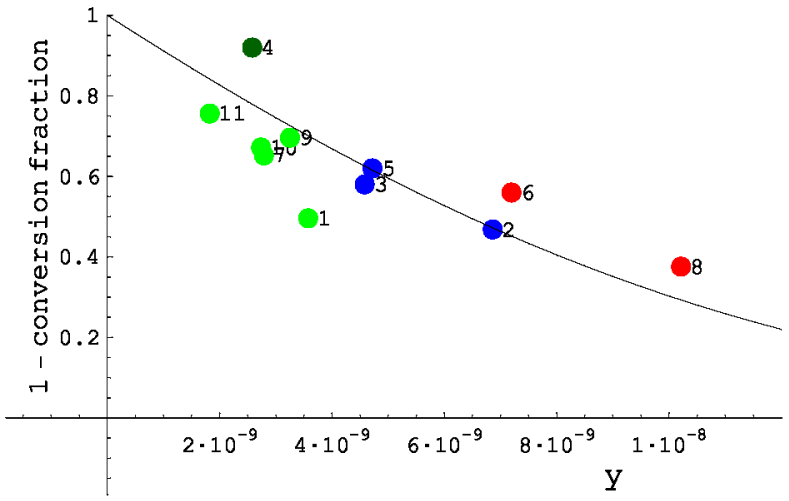

Figure 2. Data and best-fit curve for the reaction rate from Test Series-1. The best-fit value is $k=4.512 \times$ $10^{-8} \mathrm{~m}^{3} /$ (moles $\cdot \mathrm{s}$ ).

The comparison between the predicted and the measured conversion fraction of the metal oxides in the simulant is shown in Figure 3. The data together with the best-fit curve for $\gamma$ is shown in Figure 4. It is evident from these figures that the theoretical model does capture the trend in the data. There is some scatter in the data when compared to the predictions. Test number 4 in the plot for $\gamma$ (Figure 4) appears to be an outlier. Also, in Figures 2 and 3, the data for test number 4 has a trend that is different from the 


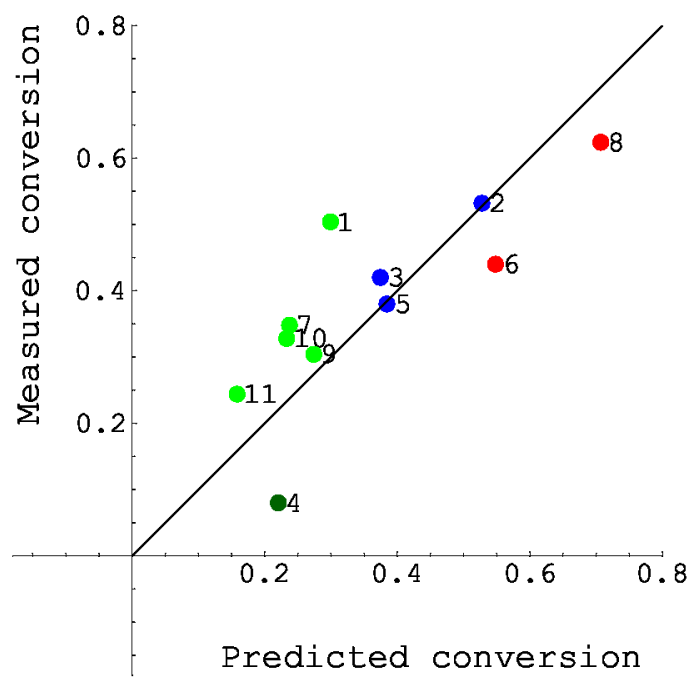

Figure 3. Comparison of measured and predicted conversion fraction from Test Series-1.

rest of the no-carbon-cap data. Indeed, the test data in Table 1 shows that for test number 4, the amount of regolith processed is high and the oxygen yield is low relative to the other tests. For these reasons, a dark green symbol has been used for test number 4 in all the plots.

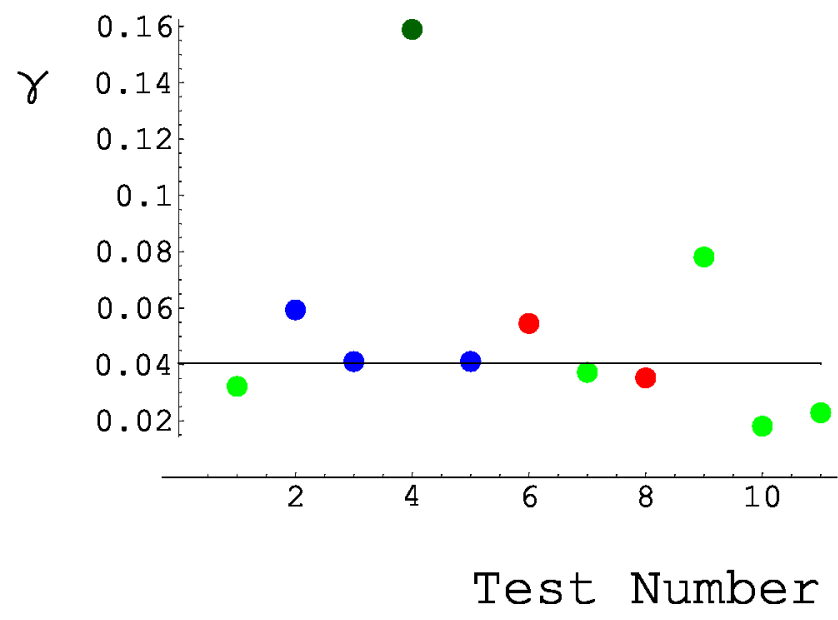

Figure 4. Data and best fit curve for the pyrolysis constant from Test Series-1. The best-fit value is $\gamma=0.0404$ $\mathrm{m} / \mathrm{s}$.

There appears to be a trend in Figures 2 and 3 with respect to carbon cap formation. A carbon cap does not occur when the conversion fraction of the metal oxides is low. When a carbon cap is formed, the conversion fraction is high, and is typically above 0.4. The trend is reasonable because, when the conversion fraction of the metal oxide is high, the amount of unreacted metal oxide in the melt is low, and therefore, the reaction rate in the melt is relatively slow. Thus, the amount of unreacted carbon in the melt would be high, and there is increased resistance for additional carbon that is deposited on the surface to go into solution in the melt. One might anticipate that there is a tendency for the carbon deposited on the surface to agglomerate and form a layer or cap on the surface.

The analysis of the data that has been performed assumes $k$ and $\gamma$ to be constants, independent of temper- 
ature and pressure. In the Test Series 1 data, the processing temperature varies from $1640^{\circ} \mathrm{C}$ to $1913^{\circ} \mathrm{C}$, and the pressure varies from 3 psi to 15 psi. These variations are accounted for in the data analysis by their effect on the gas density. One might speculate that there may be additional temperature and pressure dependencies that are not captured in the model if $k$ and $\gamma$ were to depend on temperature and pressure. It is an open question whether the data scatter in the figures might be due to these temperature and pressure dependencies. Since the data in Table 1 is scarce, further test data is likely necessary to explore such dependencies. These features need to be addressed in the future.

\section{Conclusion}

The comparison of ORBITEC's Test Series 1 data with our model of the pyrolysis of methane and reaction of the deposited carbon with the metal oxide in the melt yields a surface reaction rate of $\gamma=0.0404 \mathrm{~m} / \mathrm{s}$ and a melt reaction rate of $k=4.512 \times 10^{-8} \mathrm{~m}^{3} /($ moles $\cdot \mathrm{s})$. The data encompasses processing temperature from $1640^{\circ} \mathrm{C}$ to $1913^{\circ} \mathrm{C}$, processing pressure from $3 \mathrm{psi}$ to $15 \mathrm{psi}$, methane flow rate from $6.05 \mathrm{sccm}$ to $17.18 \mathrm{sccm}$, and a processing time of $80 \mathrm{~min}$. With the best-fit values of $\gamma$ and $k$, the model predictions for the amount of metal oxide that is converted compares favorably with the experimentally measured conversions over the entire range of test conditions. Thus the model can be used with a good degree of confidence to predict the behavior of larger scale carbothermal reactors. One aspect that needs to be understood is the scatter in the data when compared with the model predictions, and whether temperature and pressure dependencies of $\gamma$ and $k$ can explain or reduce the scatter.

\section{References}

${ }^{1}$ G.B. Sanders, W.E. Larson, K.R. Sacksteder and C.A. Mclemore, "NASA In-Situ Resource Utilization (ISRU) Project Development \& Implementation," Space 2008 Conference and Exposition, September 2008, San Diego, California.

${ }^{2}$ S.D. Rosenberg, R.L. Beegle, Jr, G.A. Guter, F.E., Miller, M. Rothenberg, The onsite manufacture of propellant oxygen from lunar resources, In NASA. Johnson Space Center, Space Resources, Volume 3: Materials, 162-185, 1991 (SEE N93-16875 05-91).

3 www.orbitec.com

${ }^{4}$ R. Balasubramaniam, U. Hegde and S. Gokoglu, "Carbothermal Processing of Lunar Regolith Using Methane," CP969, STAIF 2008, M.S. El-Genk (ed.), American Institute of Physics 979-0-7354-0486-1/08, pp. 157-161.

${ }^{5}$ Orbital Technologies Corporation: Monthly Progress Report Number 24 on Carbothermal Reduction of Lunar Regolith OTC-GS0167-PR-07-24, 31 May 2007.

${ }^{6}$ E. Hill,M.J. Mellin, B. Deane, Y. Liu, and L.A. Taylor, "Apollo sample 70051 and high- and low-Ti lunar soil simulants MLS-1A and JSC-1A: Implications for future lunar exploration," J. Geophysical Research, Vol. 112, E02006, doi:10.1029/2006JE002767, 2007.

${ }^{7}$ ORBITEC, "Carbothermal Reduction of Lunar Regolith," Phase 1 Final Report OTC-GS0167-FR-06-1, Orbital Technologies Corporation (ORBITEC), Madison, Wisconsin, USA, 29 September 2006. 


\begin{tabular}{|c|c|c|c|c|c|}
\hline \multicolumn{5}{|c|}{ REPORT DOCUMENTATION PAGE } & $\begin{array}{l}\text { Form Approved } \\
\text { OMB No. 0704-0188 }\end{array}$ \\
\hline \multicolumn{6}{|c|}{ 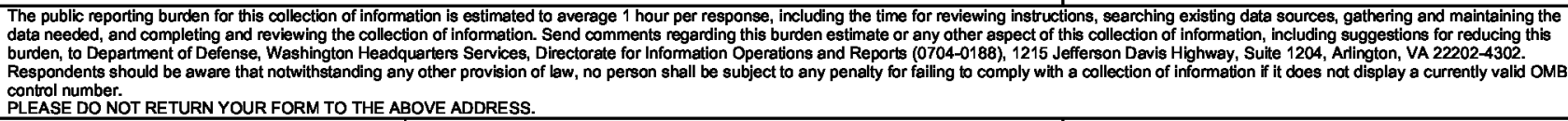 } \\
\hline \multicolumn{2}{|c|}{$\begin{array}{l}\text { 1. REPORT DATE (DD-MM-YYYY) } \\
01-07-2009\end{array}$} & \multicolumn{3}{|c|}{$\begin{array}{l}\text { 2. REPORT TYPE } \\
\text { Technical Memorandum }\end{array}$} & 3. DATES COVERED (From - To) \\
\hline \multirow{2}{*}{\multicolumn{5}{|c|}{$\begin{array}{l}\text { 4. TITLE AND SUBTTLE } \\
\text { Determination of Chemical Kinetic Rate Constants of a Model for Carbothermal Processing } \\
\text { of Lunar Regolith Simulant Using Methane }\end{array}$}} & 5a. CONTRACT NUMBER \\
\hline & & & & & 5b. GRANT NUMBER \\
\hline & & & & & 5c. PROGRAM ELEMENT NUMBER \\
\hline \multirow{3}{*}{\multicolumn{5}{|c|}{$\begin{array}{l}\text { 6. AUTHOR(S) } \\
\text { Balasubramaniam, R.; Gokoglu, S.; Hegde, U. }\end{array}$}} & 5d. PROJECT NUMBER \\
\hline & & & & & 5e. TASK NUMBER \\
\hline & & & & & $\begin{array}{l}\text { 5f. WORK UNIT NUMBER } \\
\text { WBS 387498.04.01.05.01.03 }\end{array}$ \\
\hline \multicolumn{5}{|c|}{$\begin{array}{l}\text { 7. PERFORMING ORGANIZATION NAME(S) AND ADDRESS(ES) } \\
\text { National Aeronautics and Space Administration } \\
\text { John H. Glenn Research Center at Lewis Field } \\
\text { Cleveland, Ohio 44135-3191 }\end{array}$} & $\begin{array}{l}\text { 8. PERFORMING ORGANIZATION } \\
\text { REPORT NUMBER } \\
\text { E-16933 }\end{array}$ \\
\hline \multirow{2}{*}{\multicolumn{5}{|c|}{$\begin{array}{l}\text { 9. SPONSORING/MONITORING AGENCY NAME(S) AND ADDRESS(ES) } \\
\text { National Aeronautics and Space Administration } \\
\text { Washington, DC 20546-0001 }\end{array}$}} & $\begin{array}{l}\text { 10. SPONSORING/MONITOR'S } \\
\text { ACRONYM(S) } \\
\text { NASA; AIAA }\end{array}$ \\
\hline & & & & & $\begin{array}{l}\text { 11. SPONSORING/MONITORING } \\
\text { REPORT NUMBER } \\
\text { NASA/TM-2009-215617; AIAA-2009- } \\
1390 \\
\end{array}$ \\
\hline \multicolumn{6}{|c|}{$\begin{array}{l}\text { 12. DISTRIBUTION/AVAILABILITY STATEMENT } \\
\text { Unclassified-Unlimited } \\
\text { Subject Category: } 31 \\
\text { Available electronically at http://gltrs.grc.nasa.gov } \\
\text { This publication is available from the NASA Center for AeroSpace Information, 433-757-5802 }\end{array}$} \\
\hline \multicolumn{6}{|c|}{ 13. SUPPLEMENTARY NOTES } \\
\hline \multicolumn{6}{|c|}{$\begin{array}{l}\text { 14. ABSTRACT } \\
\text { We have previously developed a chemical conversion model of the carbothermal processing of lunar regolith using methane to predict the } \\
\text { rate of production of carbon monoxide. In this carbothermal process, gaseous methane is pyrolyzed as it flows over the hot surface of a } \\
\text { molten zone of lunar regolith and is converted to carbon and hydrogen. Hydrogen is carried away by the exiting stream of gases and carbon } \\
\text { is deposited on the melt surface. The deposited carbon mixes with the melt and reacts with the metal oxides in it to produce carbon } \\
\text { monoxide that bubbles out of the melt. In our model, we assume that the flux of carbon deposited is equal to the product of the surface } \\
\text { reaction rate constant } \gamma \text { and the concentration of methane adjacent to the melt surface. Similarly, the rate of consumption of carbon per unit } \\
\text { volume in the melt is equal to the product of the melt reaction rate constant } k \text { and the concentrations of carbon and metal oxide in the melt. } \\
\text { In this paper, we describe our effort to determine } \gamma \text { and } k \text { by comparison of the predictions from our model with test data obtained by } \\
\text { ORBITEC (Orbital Technologies Corporation). The concentration of methane adjacent to the melt surface is a necessary input to the model. } \\
\text { It is inferred from the test data by a mass balance of methane, adopting the usual assumptions of the continuously-stirred-tank-reactor model, } \\
\text { whereby the average concentration of a given gaseous species equals its exit concentration. The reaction rates } \gamma \text { and } k \text { have been determined } \\
\text { by a non-linear least-squares fit to the test data for the production of carbon monoxide and the fraction of the incoming methane that is } \\
\text { converted. The comparison of test data with our model predictions using the determined chemical kinetic rate constants provides a consistent } \\
\text { interpretation of the process over the full range of temperatures, pressures, and methane flow rates used in the tests, thereby increasing our } \\
\text { confidence to use the model for scale-up purposes. }\end{array}$} \\
\hline \multicolumn{6}{|c|}{$\begin{array}{l}\text { 15. SUBJECT TERMS } \\
\text { Carbothermal reduction; ISRU; Chemical kinetics; Modeling; Lunar regolith simulant; Lunar regolith; Lunar simulant }\end{array}$} \\
\hline \multicolumn{3}{|c|}{ 16. SECURTY CLASSIFICATION OF: } & $\begin{array}{l}\text { 17. LIMTATION OF } \\
\text { ABSTRACT }\end{array}$ & $\begin{array}{l}\text { 18. NUMBER } \\
\text { OF }\end{array}$ & $\begin{array}{l}\text { 19a. NAME OF RESPONSIBLE PERSON } \\
\text { STI Help Desk (email:help@sti.nasa.gov) }\end{array}$ \\
\hline $\begin{array}{l}\text { a. REPORT } \\
\text { U }\end{array}$ & $\begin{array}{l}\text { b. ABSTRACT } \\
\text { U }\end{array}$ & \begin{tabular}{|l|} 
c. THIS \\
PAGE \\
U \\
\end{tabular} & $\mathrm{UU}$ & $\begin{array}{c}\text { PAGES } \\
14\end{array}$ & $\begin{array}{l}\text { 19b. TELEPHONE NUMBER (include area code) } \\
\text { 433-757-5802 }\end{array}$ \\
\hline
\end{tabular}



